\title{
articles
}

\section{Epidemiology of substance use among secondary school learners in Atteridgeville, Gauteng}

\author{
S V Moodley, MB ChB, DMH (SA), DTM\&H, MMed, FCPHM (SA) \\ M J Matjila, MB ChB, MMed (Community Health) \\ Department of Public Health Medicine, School of Health Systems and \\ Public Health, University of Pretoria
}

M Y H Moosa, MB ChB, MCFP (SA), MMed (Psych), FCPsych (SA) Division of Psychiatry, School of Medicine, University of the Witwatersrand

Introduction. Adolescent substance use has a number of adverse consequences for both the individual and society. Anecdotal evidence suggested the existence of a serious substance use problem among learners in Atteridgeville, part of the City of Tshwane Metropolitan Municipality in Gauteng, South Africa.

Objectives. The objectives of the study were to determine the prevalence rates and age of initiation of substance use among learners attending secondary schools in Atteridgeville, and the factors, if any, associated with cannabis use.

Methods. This was a cross-sectional study. A cluster sampling technique was employed. Twenty-two of the total of 191 grade 8 - 11 classes in the nine Atteridgeville secondary schools were randomly selected, with all 895 learners in the selected classes being invited to participate. Self-administered questionnaires were used to collect data. Statistical analysis was conducted using the survey estimation commands in STATA 10.0..

Results. The lifetime prevalence rates for the three most commonly used substances were 51.4\% (95\% confidence interval (Cl) 41.5 - 61.5\%) for alcohol, 25.2\% (95\% Cl 17.1 - 33.3\%) for cigarettes and 13.2\% (95\% Cl 8.3 - 18.2\%) for cannabis. Alcohol was also found to have the lowest mean age of initiation at 14.6 years (standard deviation 2.0). Based on CRAFFT screening scores, 30.3\% (95\% Cl $24.5-36.1 \%$ ) of learners met the criteria for possible problem substance use. Following multivariate analysis, the factors found to be significantly associated with lifetime cannabis use were age, gender, lifetime cigarette use, lifetime alcohol use, the number of illicit drug users among the learners' five closest friends, and an older sibling with a history of illicit drug use.

Conclusion. The results of the study suggest that substance use among learners in Atteridgeville is widespread and that a comprehensive intervention strategy is required.

Adolescent substance use is a serious concern owing to potential short- and long-term outcomes for the health and safety of the individual as well as the number of associated adverse social consequences. ${ }^{1-6}$ The association between heavy episodic adolescent alcohol use and road traffic accidents, suicide, violence and high-risk sexual behaviour is well documented., ${ }^{2,3}$ There is evidence that excessive alcohol use in adolescence leads to alcohol dependence, illicit substance use and criminal behaviour in adulthood. ${ }^{2,4}$ Short-term consequences of cannabis use include high-risk sexual behaviour and an increase in sexually transmitted infections. ${ }^{5}$ Frequent use of cannabis can result in dependence and psychosis. ${ }^{6}$

Over the past decade a few studies have assessed the epidemiology of substance use among South African learners. The first South African National Youth Risk Behaviour Survey ${ }^{7}$ was conducted among grade 8 - 11 learners in 2002 and reported prevalence rates of $31.8 \%$ for past-month alcohol use, $23.0 \%$ for past-month binge drinking and $9.1 \%$ for past-month cannabis use. Based on the results of the three Global Youth Tobacco Surveys, there has been a decline in cigarette smoking among grade 8 - 10 learners in South Africa between 1999 and 2008.,9 The prevalence of lifetime cigarette smoking fell from $46.7 \%$ in 1999 to $37.6 \%$ in 2002 , with a further decline to $34.0 \%$ in 2008.89 The prevalence rate of past-month cigarette use was found to be $23.0 \%$ in the 1999 survey, $18.5 \%$ in the 2002 survey and $16.5 \%$ in the 2008 survey. 8,9

At a regional level, a study conducted among high-school pupils in rural KwaZulu-Natal found alcohol to be the most commonly used substance, followed by inhalants and cannabis. ${ }^{10}$ The lifetime prevalence among township secondary school learners in four education districts in the Free State was found to be above $40 \%$ for alcohol use and approximately $5 \%$ for cannabis use. ${ }^{11}$ A study among grade 6 and 7 learners in four primary schools in an historically disadvantaged area in Tshwane, Gauteng, found lifetime prevalences of alcohol and cannabis use of $27 \%$ and $7 \%$, respectively, and past-month prevalence rates of $14 \%$ for alcohol and $4 \%$ for cannabis. ${ }^{12}$

The association between substance use by learners and several demographic, environmental, scholastic, psychological and social factors has been investigated. South African studies have consistently found higher rates of substance use in male learners than female learners. ${ }^{10,13}$ Several studies have found that older learners report significantly higher rates of substance use than younger ones. ${ }^{13-15}$ A study conducted among adults in three communities in Cape Town found that poverty-related factors were associated with substance use, ${ }_{1}^{16}$ but in a study involving Cape Town learners no significant association was found between substance use and a proxy indicator of socio-economic status. ${ }^{17}$ Reddy et al. ${ }^{3}$ found that past-month alcohol and cannabis use was associated with poor academic performance among learners in South Africa. There is evidence that parental substance use 
increases the likelihood of adolescent substance use. ${ }^{18}$ SimonsMorton ${ }^{19}$ found that alcohol use by an adolescent was related to the number of drinkers among the individual's five closest friends. Peers were found to have had a greater influence on learners initiating substance use than the family, school and media among learners in the Free State."

The present study was conducted in Atteridgeville, South Africa. Atteridgeville is a township located south-west of the Pretoria central business district and forms part of the City of Tshwane Metropolitan Municipality. ${ }^{20}$ Established in 1939 by the then government as a township for black Africans, it is today home to approximately 250000 people..$^{20}$ There are nine high schools in Atteridgeville. A number of media reports since 2006 have highlighted the existence of substance use, particularly the use of a combination of cannabis, heroin and cutting agents, a combination referred to locally as nyaope, by learners in Atteridgeville. The objectives of this study, conducted among learners attending high schools in Atteridgeville, were to determine the prevalence of use of various substances, the age of initiation of substance use, the proportion of learners who may require further intervention for their substance use, and the factors associated with cannabis use.

\section{Methods}

\section{Design and sampling}

This was a cross-sectional study of learners attending the nine high schools in Atteridgeville. Because grade 12 learners were preparing for national examinations they were excluded from the survey, as were learners who were absent on the day of the survey. A singlestage cluster sampling technique was employed with each class of learners being regarded as a primary sampling unit. A single sequential list was compiled of all 191 grade 8 - 11 classes in the nine secondary schools. Twenty-two classrooms were then selected from this list by simple random sampling. All the learners in the selected 22 classrooms were invited to participate in the survey.

\section{Measurement tools}

The measurement tool for learners was a self-administered questionnaire, available in English and Northern Sotho (Sepedi). It included questions related to socio-demographic characteristics, socio-economic characteristics, scholastic characteristics, use of alcohol, cigarettes and illicit substances, sites where substances were obtained and family and peer alcohol and drug use. It also comprised of the CRAFFT screening instrument. The CRAFFT score is derived from six questions. ${ }^{21}$ Based on the findings and recommendations of Knight et al., ${ }^{21}$ we regarded a CRAFFT score of 2 or more as indicating possible problem substance use requiring further assessment. ${ }^{21}$ The CRAFFT screening tool was preferred to other instruments because it was designed specifically for adolescents and screens for multiple substances, and the questions are easy to understand. ${ }^{21,22}$ The validity and reliability of the CRAFFT tool have been tested in various settings, ${ }^{21,23,24}$ but it should be noted that no validation studies on the CRAFFT tool have been conducted in South Africa. Knight et al. ${ }^{21}$ found that validity of the instrument was not significantly influenced by gender, race or age. In a recent review by Dhalla et al..$^{24}$ of the CRAFFT's psychometric properties, the instrument's internal consistency was found to be between 0.65 and 0.86 , sensitivity between 0.61 and 1.00 and specificity between 0.33 and 0.97 . The values for validity were obtained at optimal cutpoints. $^{24}$

\section{Ethical considerations and procedures}

The study received ethics approval from the Research and Ethics Committee of the University of Pretoria. Authorisation to conduct the study was granted by the Gauteng Department of Education. A 'passive' parental consent procedure was employed. A leaflet was sent to the learners' guardians, which gave them information about the nature of the research and their right to refuse their child's participation. A refusal form was attached to the leaflet. If this form was not returned, it was assumed that consent had been given by a learner's guardian. Informed assent was then sought from those learners whose parents did not refuse to allow them to participate. Those learners whose parents did not want them to participate were not given a questionnaire, and those who themselves wished not to participate were asked to leave the questionnaire blank.

\section{Data analysis}

All data were analysed using the statistical package STATA version 10.0. As cluster sampling was employed in the study, statistical analysis needed to take intra-cluster correlation into account. This was accomplished by using the survey estimation commands in STATA. Prevalence rates with 95\% confidence intervals (Cls) were calculated for lifetime and past month use of various substances. Frequencies and summary statistics were obtained for age of initiation of substance use. A total CRAFFT score was calculated for each participant, and the proportion of learners with a CRAFFT score of two or more was determined. Multiple logistic regression was used to determine the factors associated with lifetime cannabis use. The independent variables that were significantly associated with lifetime cannabis use at a significance level of $90 \%$ in bivariate analysis were entered into the initial full regression model. Backwards stepwise regression was then carried out.

\section{Results}

A total of 22 classes comprising 895 learners were invited to participate in the study. Eight hundred and nine learners completed questionnaires, which equates to a response rate of $90.4 \%$. A total of 81 (9.1\%) learners who were invited to participate were absent on the days of data collection. Excluding those who were absent, the response rate would be $99.4 \%$ (809/814).

As the sample of classes was randomly selected, the participants were not evenly distributed by grade. Of the 809 participants, 232 (28.7\%) were in grade 8, 101 (12.5\%) in grade 9, 194 (24.0\%) in grade 10 and 282 (34.9\%) in grade 11. The mean age of learners participating in the study was 16.2 years (standard deviation (SD) 1.8). The sample consisted of marginally more females (50.3\%) than males (49.8\%). All the learners were black Africans. 


\section{Prevalence rates of substance use}

Alcohol was the substance most commonly used by the learners, followed by cigarettes and cannabis. Over half of the study participants (51.4\%) had consumed alcohol at some point in their lives. The prevalence of alcohol use for the past month was 18.1\%. Of the 146 learners who had reported alcohol use in the past month, 75 (51.4\%) exhibited a binge drinking pattern ( 5 or more drinks on a single day) on at least one day in the past month. Table 1 details the lifetime prevalence rates of various substances (with $95 \% \mathrm{Cls}$ ) as well the pastmonth prevalence rates of the most commonly used substances.

When substance use was stratified by grade and gender, the highest prevalence rates among the participants for lifetime and pastmonth alcohol, cigarette and cannabis use was found among grade 11 males. For all grades, males had higher lifetime alcohol, cigarettes and cannabis prevalence rates than females. With the exception of grade 8 , males had higher rates of past-month alcohol use, pastmonth binge drinking and past-month cigarette use than females. For males there was a trend for past-month alcohol use, past-month binge drinking and past-month cannabis use to increase with grade, but with most of the $95 \%$ Cls overlapping. There were no consistent grade trends for females for past-month use of any of the substances. The lifetime and past-month prevalence rates for alcohol, cigarettes and cannabis stratified by grade and gender are set out in Table 2.

\section{Age of initiation of substance use}

The mean age in years of first use of alcohol, cigarettes, cannabis and nyaope among the participants was 14.6 (SD 2.0), 14.8 (SD 2.3), 15.1

\begin{tabular}{llll}
\multicolumn{4}{l}{ Table 1. Prevalence rates of substance use } \\
\hline Substance $(\boldsymbol{N})$ & $\boldsymbol{N}$ & Prevalence (\%) & $\mathbf{9 5 \%} \mathbf{C l}$ \\
Lifetime use & & & \\
$\quad$ Alcohol (806) & 415 & 51.4 & $41.5-61.5$ \\
Cigarettes (787) & 198 & 25.2 & $17.1-33.3$ \\
Cannabis (793) & 105 & 13.2 & $8.3-18.2$ \\
Glue (720) & 46 & 6.4 & $4.0-8.8$ \\
Nyaope (780) & 23 & 2.9 & $1.1-4.8$ \\
Heroin (713) & 7 & 1.0 & $0.3-1.6$ \\
Cocaine (711) & 6 & 0.8 & $0.2-1.5$ \\
Mandrax (712) & 5 & 0.7 & $0.1-1.3$ \\
Tik (712) & 5 & 0.7 & $0.0-1.3$ \\
LSD (712) & 5 & 0.7 & $0.1-1.3$ \\
Past month use & & & $6.8-17.9$ \\
Alcohol (805) & 146 & 18.1 & $2.2-8.4$ \\
Alcohol binge drinking (800) & 75 & 9.4 & $10.8-25.4$ \\
Cigarette (785) & 97 & 12.4 & $4.6-14.1$ \\
Cannabis (790) & 42 & 5.3 & \\
& & & \\
\hline
\end{tabular}

Table 2. Prevalence rates $(\%(95 \% \mathrm{CI}))$ of alcohol, cigarette and cannabis use, by grade and gender

\begin{tabular}{|c|c|c|c|c|c|}
\hline & Grade 8 & Grade 9 & Grade 10 & Grade 11 & Overall \\
\hline \multicolumn{6}{|c|}{ Lifetime alcohol use } \\
\hline Females & $28.3(22.2-34.3)$ & $32.7(26.0-39.4)$ & $42.0(26.1-58.0)$ & $63.4(48.7-78.1)$ & $45.1(35.1-55.0)$ \\
\hline Males & $31.0(21.0-40.9)$ & $55.3(33.6-77.0)$ & $65.7(51.9-79.5)$ & $77.5(64.0-94.1)$ & $58.3(46.2-70.4)$ \\
\hline \multicolumn{6}{|c|}{ Past-month alcohol use } \\
\hline Females & $6.2(1.4-11.0)$ & $9.6(5.3-13.8)$ & $6.9(2.8-11.0)$ & $24.8(16.4-33.3)$ & $13.8(8.3-19.3)$ \\
\hline Males & $4.4(0.0-10.0)$ & $14.9(8.4-21.4)$ & $17.8(11.2-24.5)$ & $44.1(28.5-59.8)$ & $22.3(12.5-32.0)$ \\
\hline \multicolumn{6}{|c|}{ Past-month binge drinking } \\
\hline Females & $1.8(0.0-4.1)$ & $1.9(0.0-5.2)$ & No observations & $8.6(2.1-15.0)$ & $4.0(1.0-7.0)$ \\
\hline Males & $2.6(0.0-6.1)$ & $8.5(1.8-15.3)$ & $11.0(6.5-15.4)$ & $30.7(20.5-40.9)$ & $14.7(7.8-21.6)$ \\
\hline \multicolumn{6}{|c|}{ Lifetime cigarette use } \\
\hline Females & $8.3(0.6-15.9)$ & $8.2(0.0-18.4)$ & $4.8(0.0-1.0)$ & $30.6(17.3-44.0)$ & $15.9(7.9-24.0)$ \\
\hline Males & $10.4(0.5-15.8)$ & $27.1(19.9-34.2)$ & $34.3(24.7-44.0)$ & $57.0(44.7-69.3)$ & $33.8(23.2-44.5)$ \\
\hline \multicolumn{6}{|c|}{ Past-month cigarette use } \\
\hline Females & $3.7(0.0-8.1)$ & $6.1(0.0-12.9)$ & $2.4(0.0-7.7)$ & $10.2(4.6-15.8)$ & $6.2(2.8-9.6)$ \\
\hline Males & $2.6(0.0-6.2)$ & $25.0(16.9-33.1)$ & $14.1(0.0-30.2)$ & $31.5(21.5-41.5)$ & $17.8(9.7-25.8)$ \\
\hline \multicolumn{6}{|c|}{ Lifetime cannabis use } \\
\hline Females & $3.5(0.7-7.8)$ & No observations & $1.2(0.0-3.7)$ & $3.3(0.0-7.1)$ & $2.5(0.4-4.5)$ \\
\hline Males & $8.1(3.4-12.8)$ & $17.0(12.8-21.3)$ & $18.1(8.1-28.3)$ & $44.5(33.0-56.1)$ & $23.9(15.3-32.6)$ \\
\hline \multicolumn{6}{|c|}{ Past-month cannabis use } \\
\hline Females & $1.8(0.0-5.7)$ & No observations & No observations & No observations & $0.5(0.0-1.6)$ \\
\hline Males & $0.9(0.0-2.6)$ & $6.4(0.0-12.9)$ & $8.1(1.1-15.1)$ & $21.4(10.2-32.6)$ & $10.2(4.3-16.2)$ \\
\hline
\end{tabular}


(SD 2.2) and 15.8 (SD 2.6), respectively. The distribution of age of first use of alcohol, cigarettes, cannabis and nyaope is displayed in Fig. 1. Some of the participants had first started using alcohol, cigarettes and cannabis while still at primary school. A significant number of participants who had ever used alcohol had had their first alcoholic drink by the age of 14 , with the vast majority of participants having had their first drink by the age of 16 . First use of cigarettes and cannabis among the participants occurred mainly between the ages of 14 and 17 years and 15 and 17 years, respectively. First use of nyaope most commonly occurred at 17 years of age.

\section{CRAFFT scores}

Of the 697 learners who completed the CRAFFT component of the questionnaire, $46.9 \%$ (95\% Cl 40.4 - 53.3\%) scored a total of zero, $23.9 \%$ (Cl 20.9-26.8\%) scored a total of 1, and 30.3\% (Cl $24.5-36.1 \%)$ scored a total of 2 or more on the CRAFFT, indicating possible problem use. The highest proportion of CRAFFT scores of 2 or more among the participants was found among grade 11 males, viz. $50.4 \%$. Overall significantly more males (37.5\%) than females $(22.7 \%)$ had CRAFFT scores of more than 2, with a design-based chi-square of 21.5072 and a $p$-value of 0.0001 . Table 3 displays the proportion of participants who scored 2 or more for the CRAFFT when stratified by grade and gender.

\section{Factors associated with lifetime use of cannabis}

The variables that maintained a significant association with lifetime cannabis use following multiple logistic regression analysis are displayed in Table 4. Male gender, age 17 years and older, lifetime cigarette use, lifetime alcohol use and older sibling illicit drug use were associated with significantly higher odds of lifetime cannabis use. An increase in the number of illicit drug users among five closest friends also significantly increased the odds of lifetime cannabis use.

\section{Discussion}

The finding that alcohol is the substance most commonly used by learners in Atteridgeville is consistent with studies conducted among learners in other parts of South Africa. 10,11,25 When considering substance use by gender, males in this study generally had higher prevalence rates than females. A striking finding of the Atteridgeville study is the high lifetime prevalence of alcohol use in female learners when compared with black female learners in previous South African studies.10,17 The higher rates of lifetime alcohol use in female learners in Atteridgeville may be part of a national trend of increased use of alcohol among black female learners in the period since those studies were conducted.
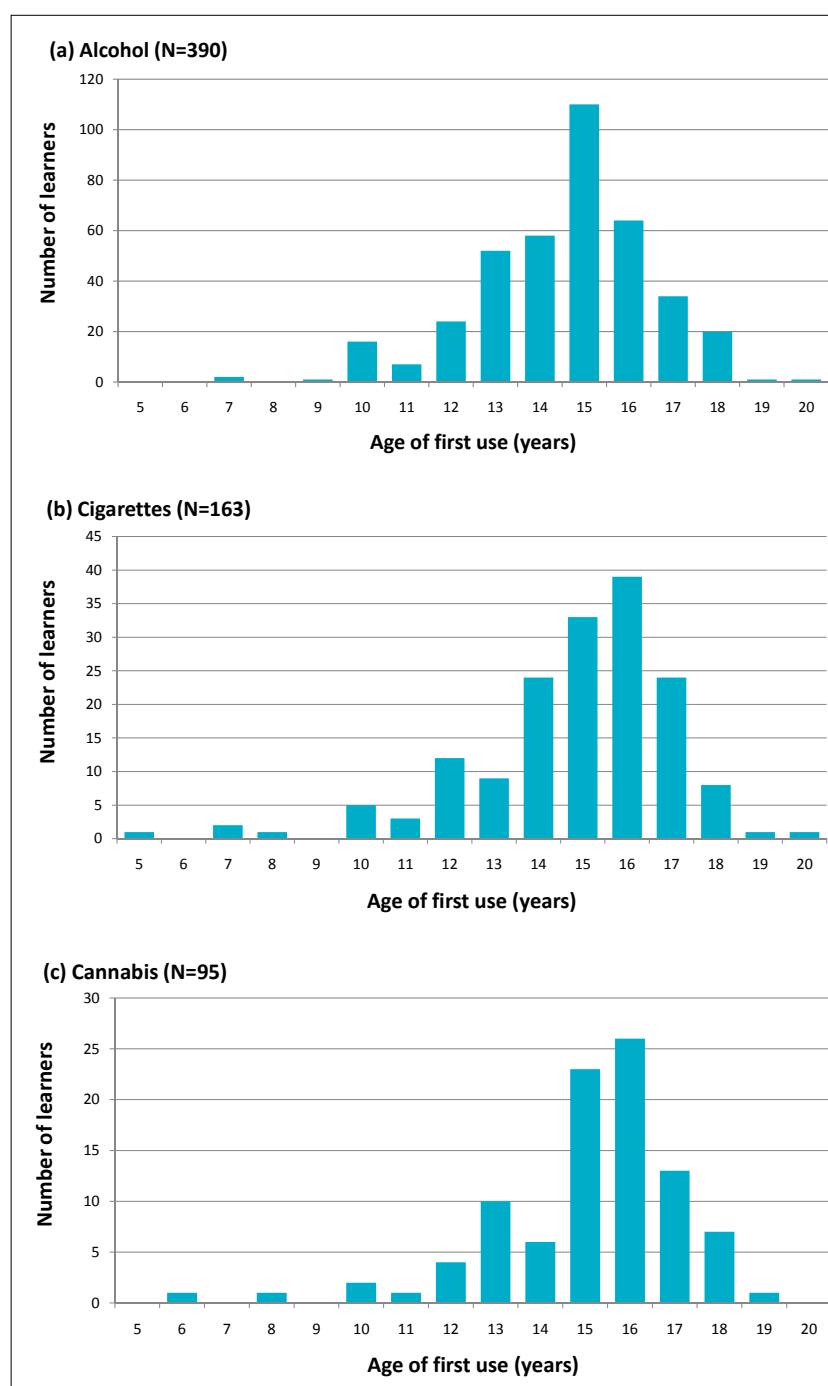

(d) Nyaope ( $\mathrm{N}=13)$

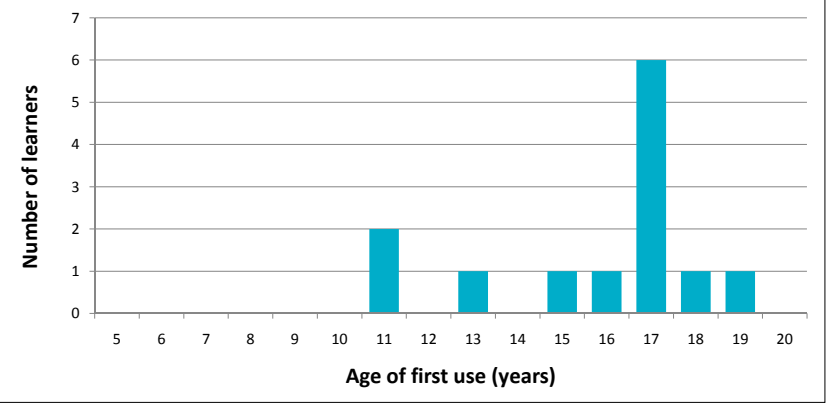

Fig. 1. Distribution of age of initiation of alcohol, cigarettes, cannabis and nyaope use among study participants.

Table 3. Proportion of participants $(\%(95 \% \mathrm{CI}))$ with a CRAFFT score of 2 or more, by grade and gender $(\mathrm{N}=697)$

\begin{tabular}{|c|c|c|c|c|c|}
\hline & Grade 8 & Grade 9 & Grade 10 & Grade 11 & Overall \\
\hline Female & $17.2(12.3-22.1)$ & $26.2(9.7-42.7)$ & $16.0(12.1-19.9)$ & $29.1(25.1-33.1)$ & $22.7(18.4-26.9)$ \\
\hline Male & $21.3(14.1-28.5)$ & $38.5(23.1-58.9)$ & $36.6(18.6-54.6)$ & $50.4(43.1-57.7)$ & $37.5(29.1-45.9)$ \\
\hline Overall & $19.6(14.5-24.7)$ & $31.7(14.3-49.1)$ & $28.1(17.6-38.5)$ & $39.2(33.4-45.0)$ & $30.3(24.5-36.1)$ \\
\hline
\end{tabular}




\begin{tabular}{|c|c|c|}
\hline Variable & $\begin{array}{c}\text { Odds ratio } \\
(95 \% \mathrm{Cl})\end{array}$ & $p$-value \\
\hline Age group (yrs) & & 0.002 \\
\hline $13-16$ & 1 & \\
\hline 17 and above & $4.29(1.83-10.04)$ & \\
\hline Gender & & $<0.001$ \\
\hline Female & 1 & \\
\hline Male & $22.60(7.17-71.27)$ & \\
\hline Older sibling illicit drug history & & 0.007 \\
\hline No & 1 & \\
\hline Yes & $4.21(1.55-11.43)$ & \\
\hline $\begin{array}{l}\text { Number of illicit drug users } \\
\text { among } 5 \text { closest friends } \\
\text { (continuous variable) }\end{array}$ & $1.63(1.17-2.27)$ & 0.006 \\
\hline Lifetime alcohol use & & $<0.001$ \\
\hline No & 1 & \\
\hline Yes & $19.98(6.64-60.06)$ & \\
\hline Lifetime cigarette use & & $<0.001$ \\
\hline No & 1 & \\
\hline Yes & $6.80(2.72-17.01)$ & \\
\hline \multicolumn{3}{|c|}{$\begin{array}{l}\text { *Multiple logistic regression. Variables originally entered in model: grade categories, age catego } \\
\text { ries, gender, number of days absent categories, repeated a grade, lifetime alcohol use, lifetime } \\
\text { cigarette use, parental illicit drug history, sibling illicit drug history and number of illicit drug } \\
\text { users among five closest friends. }\end{array}$} \\
\hline
\end{tabular}

The wide gender difference in cannabis use in this study has been demonstrated previously among black learners in other studies, 9,10,17 Visser and Routledge ${ }^{26}$ suggest that differing male and female social roles could be one of the explanations for gender differences in the prevalence of substance use. According to Masitsa, ${ }^{11}$ cannabis use by females has historically been considered taboo amongst black people in South Africa.

In this study alcohol was found to have the lowest mean age of initiation, followed by cigarette smoking and cannabis. This study confirms the findings of the first South African National Youth Risk Behaviour Survey ${ }^{7}$ and a study conducted among primary school learners in the Tshwane metropolitan area, both of which reported that a significant number of learners use alcohol and cigarettes for the first time while still at primary school.7.12 In addition, the Atteridgeville study found that some learners had used cannabis while still at primary school, which is consistent with the findings of Visser and Moleko. ${ }^{12}$ This finding is particularly concerning as a younger age of initiation of illicit substance use has been found to increase the risk of illicit substance abuse at a later stage. ${ }^{27}$

This study did not specifically address the frequency and quantity of each substance being used, in order to keep the questionnaire as concise as possible. Instead the CRAFFT screening tool was used to differentiate between respondents who may have just experimented with a substance and those who may have a substance use problem. Because the CRAFFT is a composite score based on 6 questions, it was only possible to calculate a CRAFFT score for 697 learners as a number of learners had not answered one or more of the 6 questions. The CRAFFT screening test results for Atteridgeville does suggest that that a number of learners may meet the criteria for problem use, abuse and dependence. The CRAFFT results, however, may not have been representative of the learners' recent substance use, as the questions refer to lifetime behaviour.

Multivariate analysis was used to identify the factors that were significantly associated with the lifetime use of cannabis. The finding of a significant association between learners' cannabis use and older sibling illicit drug use is consistent with the findings of a crossnational European study. ${ }^{28}$ The finding of a significant association between cannabis use and number of the five closest friends who use cannabis is consistent with the findings of Simons-Morton ${ }^{19}$ regarding alcohol use. It is also in keeping with the results of a study by Chabrol et al. ${ }^{29}$ that the number of peers using cannabis was significantly associated with cannabis use among French secondary school learners. There may be a number of explanations for this finding in the Atteridgeville study. The learner may be selecting friends with similar risk-taking behaviours, conforming to subcultural norms or being actively influenced by peers. ${ }^{30,31}$ Lifetime cannabis use was found to be significantly associated with lifetime cigarette use and lifetime alcohol use in this study. The association between cannabis and alcohol use is consistent with the findings of Taylor et al. ${ }^{10}$ in KwaZulu-Natal. These findings are also in keeping with those of Faeh et al. ${ }^{15}$ that alcohol, tobacco and cannabis use cluster in adolescents, i.e. a high proportion of adolescents use two or more of these substances.

This study had several limitations. It relied on self-reporting by learners, and it has been suggested that in survey research on substance use there may be a tendency towards under-reporting. ${ }^{32}$ In order to maximise reporting in this study, guarantees of confidentiality were given to the participants and an anonymous self-administered questionnaire was used. A number of learners failed to answer questions related to the use of 'hard' drugs. It is not clear whether this was deliberate under-reporting. The exclusion of learners absent on the day of the survey may have resulted in an underestimate of the prevalence of substance use, as a higher rate of absenteeism has been found in those who use substances. ${ }^{17}$ The cross-sectional design of the study limits the inferences that can be drawn from some of the associations found in the study, owing to uncertainty about the temporal relationship. The generalisability of the findings of this study are limited. As grade 12 learners were not included in the study, the findings only apply to grade $8-11$ learners in Atteridgeville. Generalisation of these findings to learner populations in other communities should be done with caution, as there is likely to be variation in substance use patterns between communities. 


\section{Conclusion}

This study has confirmed some important findings from previous South African and international substance use research among adolescents, including the important role of peers in an adolescent's life. In addition the results have confirmed that the concerns regarding substance use among learners in Atteridgeville are not unfounded. The high prevalence rates, combined with medical and psychosocial consequences of using these substances, highlight the public health importance of the problem and the need for urgent intervention. School-based interventions to prevent substance use should start at primary school level and incorporate methods that have been shown to be effective in countering the effect of peer pressure. It is important that national and provincial initiatives to reduce substance use among learners be strengthened, including full implementation of South Africa's National Drug Master Plan..33 Further research should be conducted, including similar studies in other communities, longitudinal studies to establish temporality, in-depth qualitative studies to understand the contemporary social determinants, and validation studies to establish the most appropriate screening tool for adolescent substance use in South Africa.

\section{References}

1. American Academy of Pediatrics. Committee on Substance Abuse. Alcohol use and abuse: a pediatric concern. Pediatrics 2001;108(1):185-189.

2. National Institute on Alcohol Abuse and Alcoholism. Underage drinking: a major public health challenge. Alcohol Alert 2003;59. http://pubs.niaaa.nih.gov/publications/aa59.htm (accessed 19 January 2009).

3. Stolle M, Sack PM, Thomasius R. Binge drinking in childhood and adolescence epidemiology, consequences, and interventions. Dtsch Arztebl Int 2009;106(19):323-328

4. Viner RM, Taylor B. Adult outcomes of binge drinking in adolescence: findings from a UK national birth cohort. J Epidemiol Community Health 2007;61(10):902-907.

5. Tonkin RS. Marijuana use in adolescence. Paediatr Child Health 2002;7(2):73-75.

6. Hall W. The mental health risks of adolescent cannabis use. PLoS Med 2006;3(2):e39.

7. Reddy SP, Panday S, Swart D, et al. Umthenthe Uhlaba Usamila - the South African Youth Risk Behaviour Survey 2002. http://www.mrc.ac.za/healthpromotion/reports.htm (accessed 23 January 2009).

8. Swart D, Reddy SP, Panday S, et al. The 2002 Global Youth Tobacco Survey (GYTS): The 2nd GYTS in South Africa (SA) - A Comparison Between GYTS (SA) 1999 and GYTS (SA) 2002 Cape Town: South African Medical Research Council, 2004. http://indicators.hst.org.za/ indicators/Behaviour/GYTS_2002.pdf (accessed 13 December 2011).

9. Reddy SP, James S, Sewpaul R, et al. The 2008 Global Youth Tobacco Survey: The 3rd GYTS in South Africa. Cape Town: South African Medical Research Council, 2010. http://indicators. hst.org.za/indicators/Behaviour/GYTS_2008.pdf (accessed 13 December 2011).

10. Taylor M, Jinabhai CC, Naidoo K, et al. An epidemiological perspective of substance use among high school pupils in rural KwaZulu-Natal. S Afr Med J 2003;93(2):136-140.
11. Masita GM. Substance use among township secondary school students - an emergent phenomenon. Africa Education Review 2007;4(1):70-88.

12. Visser M, Moleko A. High risk behaviour of primary school learners. www.sahealthinfo.org/ admodule/highrisk.htm (accessed 24 January 2009).

13. Reddy P, Resnicow K, Omardien R, et al. Prevalence and correlates of substance use among high school students in South Africa and the United States. Am J Public Health 2007;97(10):1859-1864.

14. De Micheli D, Formigoni ML. Drug use by Brazilian students: associations with family, psychosocial, health, demographic and behavioral characteristics. Addiction 2004;99(5):570-578.

15. Faeh D, Viswanathan B, Chiolero A, et al. Clustering of smoking, alcohol drinking and cannabis use in adolescents in a rapidly developing country. BMC Public Health 2006;6:169.

16. Kalichman SC, Simbayi LC, Kagee A, et al. Associations of poverty, substance use, and HIV transmission risk behaviors in three South African communities. Soc Sci Med 2006;62(7):1641-1649.

17. Flisher AJ, Parry CD, Evans J, et al. Substance use by adolescents in Cape Town: prevalence and correlates. J Adolesc Health 2003;32(1):58-65.

18. Li C, Pentz MA, Chou CP. Parental substance use as a modifier of adolescent substance use risk. Addiction 2002:97(12):1537-1550.

19. Simons-Morton B. Social influences on adolescent substance use. Am J Health Behav 2007;31(6):672-684.

20. Atteridgeville.community. http://www.atteridgeville.com (accessed 18 January 2009)

21. Knight JR, Sherritt L, Shrier LA, et al. Validity of the CRAFFT Substance Abuse Screening Test among adolescent clinic patients. Arch Pediatr Adolesc Med 2002;156(6):607-614.

22. Knight JR, Shrier LA, Bravender TD, et al. A new brief screen for adolescent substance abuse. Arch Pediatr Adolesc Med 1999;153(6):591-596

23. Knight JR, Sherritt L, Harris SK, et al. Validity of brief alcohol screening tests among adolescents: a comparison of the AUDIT, POSIT, CAGE, and CRAFFT. Alcohol Clin Exp Res 2003;27(1):67-73.

24. Dhalla S, Zumbo BD, Poole G. A review of the psychometric properties of the CRAFFT instrument: 1999-2010. Curr Drug Abuse Rev 2011;4(1):57-64.

25. Madu SN, Matla MQ. Illicit drug use, cigarette smoking and alcohol drinking behaviour among a sample of high school adolescents in the Pietersburg area of the Northern Province, South Africa. J Adolesc 2003:26(1):121-136.

26. Visser MJ, Routledge L. Substance abuse and psychological well-being of South African adolescents. South African Journal of Psychology 2007;37(3):595-615.

27. Grant BF, Dawson DA. Age of onset of drug use and its association with DSM-IV drug abuse and dependence: results from the National Longitudinal Alcohol Epidemiologic Survey. Subst Abuse 1998;10(2):163-173.

28. Kokkevi A, Richardson C, Florescu S, et al. Psychosocial correlates of substance use in adolescence: a cross-national study in six European countries. Drug Alcohol Depend 2007:86(1):67-74.

29. Chabrol H, Chauchrad E, Mabila JD, et al. Contributions of social influences and expectations of use to cannabis use in high-school students. Addict Behav 2006;31:2116-2119.

30. Fisher LA, Bauman KE. Influence and selection in the friend - adolescent relationship: findings from studies on adolescent smoking and drinking. Journal of Applied Social Psychology 1988;18:289-314.

31. Swadi H. Individual risk factors for adolescent substance use. Drug Alcohol Depend 1999;55(3):209-224

32. Harrison L, Hughes A. The validity of self-reported drug use: improving the accuracy of survey estimates. http://www.nida.nih.gov/pdf/monographs/Monograph167/ Monograph167.pdf (accessed 24 January 2009).

33. Department of Social Development, Republic of South Africa. National Drug Master Plan, 2006 - 2011. Pretoria: Department of Social Development, 2006. http//www capegateway. gov.za/other/2009/5/national_drug_master_plan_\%282006-2011\%29_a.pdf (accessed 15 November 2009). 